\title{
ISS outreach Sub-Saharan Africa: Zambia 2011
}

\author{
Johnny U. V. Monu • Duff Kopakopa • Mihra Taljanovic
}

Received: 19 July 2012 /Revised: 20 July 2012 / Accepted: 20 July 2012 /Published online: 15 August 2012

(C) ISS 2012

Insight into Radiology in 2011 - Zambia

An outreach activity was organized in collaboration with the Pan African Congress of Radiology and Imaging (PACORI) in Lusaka, Zambia, from Sept. 12-15, 2011.

Zambia is a landlocked country in South Africa with Malawi to the east, Angola to the west, Democratic Republic of the Congo to the north, and Tanzania to the northeast. To the south are Zimbabwe, Mozambique, Botswana, and Namibia. The capital city is Lusaka.

Like so many other African countries, many ethnic groups are found in Zambia, and these include the Bemba, Tonga, Chewa, Lozi, Nsenga, Tumbuka, Ngoni, Lala, Kaonde, Lunda, and other African groups. The population is approximately 13 million [1].

The infant mortality rate is 69 per 1,000 . The average life expectancy is 52.57 years ( 51.35 for men and 53.83 for women). Expenditure on health is $4.8 \%$ of the GDP and per capita income is $\$ 1,610$. The ratio of individual expenditure on health to government expenditure is 39.7 and comparable figures for Great Britain and the United States of America are 16.1 and 46.9 , respectively. The physician density is about 0.056 per 1,000 and hospital bed density is 1.9 per 1,000 [2].

There are two public medical schools and one private medical school in Zambia. Medical training in Zambia is for

J. U. V. Monu ( $\square)$

Department of Imaging Sciences, University of Rochester,

Rochester, NY, USA

e-mail: Johnny_monu@urmc.rochester.edu

D. Kopakopa

Premium Medical Services Ltd, Premium House,

Independence Avenue,

Lusaka, Zambia

M. Taljanovic

University of Arizona,

Tucson, AZ, USA
7 years after high school. Graduation from medical school is followed by 18 months of rotating internship in the core clinical disciplines of medicine, surgery, obstetrics and gynecology, and pediatrics. The premiere training institution is the University of Zambia School of Medicine located in the capital city, Lusaka. The other public medical school is also a part of the University of Zambia. It is called the Ndola School of Medicine and is located in the Copperbelt province. The only private university is called Apex Medical University, also located in Lusaka.

The government subsidizes health care by providing free health facilities for the population at the governmentowned hospitals and clinics but these are grossly inadequate. The ratio of individual expenditure on health to government expenditure is $78.3 \%$, and comparable figures for Great Britain and United States of America are $16.1 \%$ and $46.9 \%$, respectively [2]. Due to the inadequacy of the services provided by these hospitals, large segments of the population depend on private clinics for their health care needs.

There are ten radiologists in Zambia. This gives a ratio of about one radiologist per 1.3 million persons. Of the ten, two are in full-time private practice and the other eight are in public service. Three of the radiologists are indigenous Zambians who trained variously in South Africa, Tanzania, and Cuba. Sub-specialization in radiology does not exist, although some of the radiologists do have areas of interest. Currently, there is no facility for specialist training in Radiology in Zambia. While there are plans to train radiographers for extended roles, currently the existing training for radiographers does not provide for super technologist training.

All the indigenous radiologists and radiographers are members of the Radiological Society of Zambia whose main aim is to further the development of the radiology profession in the country. The Radiological Society is an affiliate of the PACORI. 
There are numerous types of radiography machines placed in all the district hospitals and large health centers. Basic ultrasound machines are also available in the district hospitals and health centers. There are five CT scanners (two public and three privately owned) and three MRI units (one public and two private) in all of Zambia. The CT and MRI scanners are only available in the large health centers in urban Zambia; namely, University Teaching Hospital, Cancer Diseases Hospital, Maina Soko Military Hospital, Fairview Hospital in Lusaka and Nkhana Mine Hospital in Kitwe. Nkhana Mine and Fairview Hospitals are privately owned while the rest are public hospitals. Away from Lusaka and the Copperbelt, the availability of radiological services is sparse. As is usually the case in most of Africa, the equipment is in frequent need of maintenance and quite often the equipment is broken down and unusable.
Radiology is clearly in its infancy in Zambia and there is a lot the developed world can do to aid advancement in radiology in this part of the world. Dialogue lines should be maintained with the radiologists especially the indigenous radiologists to identify opportunities to aid and facilitate development of the specialty.

\section{References}

1. Central Intelligence Agency. The World Factbook. Available online at https://www.cia.gov/library/publications/the-world.../geos/ ug.html. Apr 18, 2012.

2. WHO. Global Health Observatory Data Repository. http:// apps.who.int/ghodata/. 